\title{
LA DISTINTA NATURALEZA DEL DÍA Y DE LA NOCHE EN LA ANTIGÜEDAD, Y SUS DIVISIONES EN HORAS
}

\author{
The different Nature of Day and Night in the Ancient World, and their Divisions \\ into Hours
}

\author{
Daniel Gil MartíneZ ${ }^{1}$ \\ Universidad de Zaragoza \\ danielgil86@gmail.com
}

Fecha de recepción: 4-XI-2011

Fecha de aceptación: 29-XI-2011

\begin{abstract}
RESUMEN: En este artículo intento explicar las diferencias religiosas entre el día y la noche, ya que los hombres de la Antigüedad nunca comprendieron que ambas conformaran una unidad. Estudio, por tanto, las características que tuvieron el día y la noche, en especial las de esta última, en algunas de las culturas más representativas de la Antigüedad -sumeria, babilónica, egipcia, hebrea, griega, romana y celta-. Así, podemos observar que básicamente todas ellas consideran el día como un momento de vida, mientras que la noche, a menudo, es entendida como muerte y maldad. Con todo ello, podemos comprender por qué el día no fue dividido en veinticuatro horas, sino en doce diurnas y doce nocturnas.
\end{abstract}

Palabras clave: tiempo, día, noche, horas

AвSTRACT: In this article, I attempt to explain the religious differences between the day and the night because the ancients never understood both of them as a unit. I study the features of the day and especially the features of the night in several cultures of the Ancient World (Sumerian, Babylonian, Egyptian, Hebrew, Greek, Roman and Celtic). So, we can notice the day is always a moment of life while the night is often a moment of death and fear. For this reason, the day wasn't divided into 24 hours; it was actually divided into 12 hours of darkness and 12 hours of daylight.

Keywords: time, day, night, hours

1 Doctorando en Ciencias de la Antigüedad 
Si tuviéramos que buscar la unidad más lógica de tiempo, diríamos que ésta es el día, en donde el Sol, astro divinizado por la mayoría de las culturas de la Antigüedad, juega un importante papel ideológico. Pero ¿qué es el día? o, mejor dicho, ¿qué es el día y qué es la noche para los hombres de la Antigüedad? Nuestro propio lenguaje -así como nuestra cultura- nos crea un problema para entender el concepto que de estos dos momentos se tuvo en el pasado. Para las culturas más representativas de la Antigüedad -como puede ser la egipcia, sumeria, babilonia, hebrea, griega, romana y celta ${ }^{2}-$ ambos momentos se conciben con una naturaleza distinta, y además son representados mediante una o varias divinidades. Pese a estar relacionados, noche y día no componen una unidad, diferencia que debe ser entendida para comprender las divisiones del día: las horas.

El asunto debe ser tratado desde el punto de vista de las religiones, partiendo de esa máxima por la cual no hay hecho en la Antigüedad que no quede dentro de la esfera de la religión, la cual lo imbuye todo. Sin pretender realizar una profunda interpretación, intento dar una visión global, una aproximación, a estos conceptos temporales en el conjunto de la Antigüedad, observando sus principales diferencias.

\section{Vocabulario}

Si atendemos a los significados y etimologías -en los distintos lenguajes antiguos- que tienen las palabras que designan ambos momentos, éstos nos permiten observar de entrada dos concepciones distintas, que tienen que ver con una mera observación empírica de las características de la noche y el día, de la misma manera en que ya el propio Varrón nos muestra en la Lengua Latina. Éste -siguiendo a estoicos y pitagóricos-comenta que la propia naturaleza de los fenómenos «fue para el hombre la guía para poner los nombres $»^{3}$. Dicho de otro modo, los hombres primitivos captaron la naturaleza de las cosas para nombrarlas.

2 El lector podrá comprobar por sí mismo que en la enumeración, efectivamente, faltan muchas otras culturas de gran importancia. Ello se debe a que menciono sólo aquellas que van a aparecer reiteradamente a lo largo del artículo.

3 Varro, Ling. 6.2.3. De aquí en adelante, las fuentes clásicas son citadas siguiendo The Oxford Classical Dictionary. Para aquellas abreviaturas no referenciadas en dicha obra, se toman las del Diccionario Griego-Español del CSIC. 
A este respecto, nuestra moderna concepción del término «día» es citando la primera acepción que da la RAE- el «tiempo que la Tierra emplea en dar una vuelta alrededor de su eje; equivale a veinticuatro horas», pero cuando los idiomas antiguos se refieren al «día», estos términos iban encaminados -según la segunda acepción del mencionado diccionario- «al Tiempo en que el Sol está sobre el horizonte». El término en sus respectivas lenguas tiene un doble significado relacionado con la luz. La palabra sumeria $u d^{4}$ significa «día», teniendo también como significado «Sol». En acadio, urru ${ }^{5}$ posee una acepción parecida, ésta es tanto «día» como «luz».

La palabra latina dies proviene de la raíz * dei-, que significa brillar ${ }^{6}$, teniendo, por tanto, el significado de diurno, tal como se observa en Suetonio cuando dice «dies est solis praesentia»". De igual modo, Higino comenta: «diem nobis definierunt quamdiu sol ab exortu ad occasum perueniat» ${ }^{8}$.

De esta forma, las lenguas modernas han heredado un vocabulario que ha tenido que ser adaptado a una nueva concepción del tiempo. Por ello, una gran mayoría de idiomas no cuentan con una palabra concreta que designe las veinticuatro horas, quizás porque -como tendremos la oportunidad de ver- el uso de las horas en la manera en que las conocemos hoy en día es demasiado reciente.

Aunque cierto es que, ya en la Roma clásica, la palabra dies-pues de ésta proviene nuestra palabra «día» en castellano- fue tomando el significado del conjunto de la noche y el día. Dice Gémino, hacia el S. I a.C.: «Se habla de día en dos acepciones: en un sentido es el lapso de tiempo que transcurre desde la salida del Sol hasta su puesta; en otro sentido es el lapso de tiempo que transcurre desde la salida del Sol hasta la salida siguiente»?

En un pasaje de Plinio $^{10}$, que veremos más tarde, éste nos comenta que, pese a que para los matemáticos o filósofos el día era considerado, en muchas ocasiones, como una única unidad con la noche; para el resto de la

4 HALLORAN, J. (2006): entre sus significados está también el de tiempo, tiempo atmosférico y tormenta. También mencionado como $u_{4}$

5 SODEN, W. von (1966), vol. III.

6 ERNOUT, A. y MEILLET, A. (1985), pp. 174-175.

7 Suet. Rel. Reiff. 113.

8 Hyg. Poet. Astr. 4.19.

9 Gem. 6.1.

10 Plin. HN 2.77. 
población, la palabra «día» sólo era utilizada para designar la presencia de luz. De ahí el doble significado que nos da Gémino.

Pero, al igual que el día es nombrado de acuerdo a sus características -la de presencia de luz-, también la noche es designada por éstas. En egipcio antiguo existen multitud de términos, entre los que podemos destacar Ijeju, el cual, al mismo tiempo que «anochecer», significa «oscuridad». De igual forma, $u j-$ noche- se relaciona con el termino ujt-oscuridad-. O con otra de sus cualidades, el silencio - ger-, de donde proviene el término gereh noche- $-^{11}$.

Lo mismo sucede en sumerio. El término gíg ${ }^{12}$ significa «noche»y «oscurecer, negro, oscuro». De la misma manera, musu en acadio, nox en latín y nux en griego - estas dos últimas con misma raíz indoeuropea ${ }^{13}-$.

Aun con todo, esto tampoco es una máxima universal. Si tomamos en cuenta la etnología, observamos que, en Costa de Marfil, los pueblos abures tienen la palabra «ayen» para designar al conjunto de la noche y el día, al tiempo que tienen otros términos para referirse a cada una de las partes ${ }^{14}$. Y, sin irnos tan lejos, la palabra sueca dygn designa lo mismo ${ }^{15}$.

Por ello, lo primero que debemos comprender es la distinta naturaleza del día y de la noche, puesto que las culturas de la Antigüedad-como comentamos- no comprendieron nunca que ambas partes formaran un mismo conjunto, sino que su naturaleza es concebida como algo totalmente distinto, siendo ambos momentos opuestos ${ }^{16}$. De ahí que, para designar los días en su conjunto con la noche, en muchos pasajes bíblicos se realice expresando ambos términos. Ante nuestros ojos, ello parece una redundancia, pero algo lógico en una mentalidad -me refiero ahora a la Antigüedad- en donde el día sólo puede concebirse como la existencia de luz. Por tanto, cuando en la Biblia aparece la palabra día, por ejemplo los cuarenta días de ayuno de Jesús ${ }^{17}$, se está especificando que sólo durante el periodo diurno se

11 HORNUNG, E. (1956).

12 También: ñíg, gi ${ }_{6}, g e, \tilde{n i}_{6}, \tilde{n} e_{6}, m i, m e ́, k u_{10} ; \dot{g}_{25}$.

13 ERNOUT A., MEILLET, A. (1985), pp. 448-449; CHANTRAINE, P. (1999), pp. 759-760

14 LE GOFF, J. (1991), p. 214.

15 Ibid.

16 Heraclit. Fr. 77.

17 Lc. 4; Mt. 4. 
ayunaba, y no durante la noche. En el Diluvio Universal, la cita «haré llover sobre la tierra durante cuarenta días y cuarenta noches ${ }^{18}$ expresa que en ningún momento dejó de llover en ese lapso de tiempo. Las referencias al uso de esta terminología también aparecen en otros textos de la Antigüedad, como en los textos clásicos - siete días y siete noche permaneció en vela Darío por sufrir una lesión en el tobillo ${ }^{19}$, nos dice Tucídides-, así como en textos sumerios ${ }^{20}$ y egipcios. «El rey pasa el día y la noche propiciando las Dos Azuelas» ${ }^{21}$ reza uno de los fragmentos de los Textos de los Pirámides, entre los muchos ejemplos que se podrían presentar. Y en el poema de Gilgamesh: «Durante seis días y siete noches, vendavales, lluvias, huracanes y diluvio estuvieron golpeando la tierra ${ }^{22}$.

Ésta era la única manera para hacer una referencia al conjunto. Si bien, existen algunos términos que van encaminados a ello mediante la unión de ambas palabras, como sucede en griego con el vocablo nychtheméron ${ }^{23}$, proveniente de la unión de las palabras noche y día, aunque la primera evidencia de su uso es del S. I a.C. ${ }^{24}$. Algo parecido sucede en hebreo, en donde la expresión ereb boqūer ${ }^{25}$-unión de «mañana» y «tarde»- significa lo mismo.

\section{Características del díA y de LA NOCHE}

Ahora bien ¿qué naturaleza tienen ambos momentos del día? El día -la presencia del Sol- siempre es entendido como el orden y la vida, mientras que la noche es todo lo contrario, puesto que ambas son antitéticas y, a un mismo tiempo, complementarias. Generalmente de la noche surge el día, al igual que el mundo fue creado del caos en la mayoría de las cosmogonías ${ }^{26}$.

18 Gn. 7.4.

19 Thuc. 3.129.3.

20 Caben destacar, por poner algún ejemplo: The Flood story: c.1.7.4; The death of Gilgameš: c.1.8.1.3; Gilgameš, Enkidu and the nether world: c.1.8.1.4; The herds of Nanna (Nanna F): c.4.13.06. Todos los textos sumerios mencionados en éste artículo son citados de acuerdo a la catalogación realizada por The Electronic Text Corpus of Sumerian Literature.

21 Textos de las Pirámides, declaración 258.311; 259.315.

22 Gilgamesh 11.125. El texto está repleto de numerosos ejemplos similares.

23 De donde proviene nuestra palabra «nictémero» en castellano.

24 Paul. 2 Cor. 2.25.

25 Dan. 8.14.

26 Una síntesis de éstas se encuentra en MARCO SIMÓN, F. (1988). 
Pese a todo, la cuestión es mucho más compleja porque, si siempre existe en el día una cierta bondad del astro rey, la noche, en cambio, no acaba de ser del todo entendida como una maldad inconmensurable y total.

En el mundo egipcio, algunos de los pasajes del Himno a Atón ${ }^{27}$ resumen bien toda esta concepción del día como momento de vitalidad y resurgir, de la manera en que se expone a continuación en este fragmento:

Cada vez que apareces perfecto en el horizonte del cielo, oh Atón viviente, la vida comienża. Habiendo tú despuntado por oriente, has llenado toda la tierra con tus perfecciones. Eres deshumbrante, eres grande, tu resplandor se ba alzado sobre toda la tierra y tus rayos han abarcado las tierras hasta el límite de todo lo que tú has creado $[\ldots]^{28}$.

Pero este día no es homogéneo -hay una fase de crecimiento y otra de vejez, al igual que lo hay en el ser humano-. Éste es representado por tres personalidades de Re, que simbolizan tres momentos distintos. El Sol de la mañana es presidido por Jepri ${ }^{29}$-encarnado en un escarabajo o en un hombre con la cabeza suplantada por la imagen del coleóptero-, caracterizado por la juventud y la viveza; el de su plenitud por Horajty u Horus del horizonte, representado mediante un personaje hieracocéfalo coronado con un disco solar y rodeado por el ureo; y el atardecer por Atum, encarnando la promesa de vida futura, bajo la apariencia de un anciano ${ }^{30}$.

Re, por tanto, acaba muriendo al ponerse en el occidente; surgiendo la noche. Baja de la barca del día (mandjet), que surca el cielo, y sube en la barca de la noche (mesenktet $)^{31}$, enfrentándose a una multitud de peligros -sigue diciendo el ya mencionado Himno a Atón-:

27 ROBLEDO, I. (2003), pp. 52-61.

28 Himno a Atón, líneas 1-6.

29 FRANCO, I. (1994): p. 71.

30 Ibid, p. 19. En la cosmogonía de Heliópolis, éste fue también el demiurgo.

31 Libro de los Muertos XV, traducción de LARA PEINADO, F. (1989), p. 25. «El Osiris N. conoce al que está en la barca del día y la magnífica imagen que está en la barca de la noche». La primera está representada por Isis y contiene la serpiente de la eternidad, mientras que la de la noche la representa Neftis (Textos de las Pirámides, declaración 216; 222.210) y guarda el uraeus -el símbolo arquetípico de la realeza (Textos de las Pirámides, declaración 262.335), al tiempo que representa a Uadjit, una de las Dos señoras-. Las dos barcas encarnan además los ojos de Osiris. 
Cuando tu movimiento cesa y reposas por poniente, la tierra está a oscuras, como si se tratara de la muerte: los hombres tumbados en sus dormitorios, tapados y sin abrir sus ojos. Uno puede tomar todas sus pertenencias de debajo de sus cabezas sin que ellos se den cuenta. Todos los leones han salido de su guarida y todos los reptiles muerden. La oscuridad es tenebrosa, la tierra está en silencio, pues quien los creó se ha puesto por su horizonte ${ }^{32}$.

La noche, así se puede observar, es peligrosa tanto para los vivos como para los muertos. Por ello, al igual que el vivo vuelve durante la noche a su casa, el difunto lo hace a su tumba ${ }^{33}$.

Aun con todos estos males, los egipcios entienden la noche como un caos regenerador de lo viejo ${ }^{34}$-así se deja ver en el Libro de los Muertos XV-. El Sol, que viaja durante la noche por este caos -sumergido en el océano primordial Nun-, sale rejuvenecido de él todas las mañanas como una primera vez -siempre existe una mentalidad cíclica-. Re muere en la noche, desciende al mundo de los muertos -se puede equiparar con Osiris Naref- y se enfrenta a la oscuridad nocturna, resucitando:

Tu barca navega, persigues a tu enemigo. Tu carne revive, tus músculos se fortalecen, tus huesos recobran su consistencia, tus miembros se rejuvenecen; (en fin), tu alma es noble y tu poder divino. ;Vuelve tu rostro hacia el buen Occidente. ${ }^{\beta 5}$

La lucha que se produce es un enfrentamiento por mantener el orden cósmico, que corre peligro todas las noches, puesto que Re ha muerto y siempre existe la posibilidad de que este no resucite.

Pero no solo Re y, por extensión, el faraón -que es quien pone fin a la noche y da la vida a Egipto $^{36}$ - realizan este recorrido por la oscura noche. Todo individuo debe atravesarla una vez fallecido; por ello en el Libro de los Muertos distintas fórmulas van encaminadas a salir de ella -de hecho, el

32 Himno a Atón, líneas 11-20.

33 FRANKFORT, (1998), p. 169.

34 HORNUNG, E. (1999), p. 150.

35 Libro de los Muertos XV, traducción de LARA PEINADO, F. (1989) p. 26.

36 Textos de las Pirámides, declaración 222. 205; 320.515. 
primer editor del libro, Karl Richard Lepsius ${ }^{37}$, tituló los capítulos con las formulas destinadas a ello bajo el nombre de pri em hru (salir al día)-.

En general, la noche se concibe como la muerte, ya que en ella murió Osiris. La oscuridad de ésta es la extensión del mundo de los muertos, concepción que se ve mucho más clara en el Libro de la Noche del Imperio Nuevo. Esta interpretación, por otra parte, no había cambiado desde los inicios del Estado faraónico. En los antiquísimos Textos de las Pirámides nos encontramos esta misma equiparación: "paso la noche y soy concebido y nazco cada día» ${ }^{38}$.

En este último fragmento, sin embargo, se puede observar que, pese al aspecto de muerte que presenta la noche, ésta también es creadora de vida, algo que encontramos en varias ocasiones en los Textos de las Pirámides: «fue concebido por la noche, y en la noche nací» ${ }^{39}$. Así, el lugar por el que se oculta el Sol en el oeste es conocido por beneket-anj-cama de la vida-.

La noche, aun siendo antítesis de Re, es favorable para el faraón, pues ambos se alían para beneficiar a éste ${ }^{40}$. Por tanto, Re está ligado estrechamente a la noche, puesto que en el Libro de los Muertos se afirma que conoce sus secretos. En los papiros de Abusir se menciona la «noche de Re», que ha sido interpretada como el Año Nuevo, la noche en que no solo se regenera el día, sino el año ${ }^{41}$.

De la misma manera, podemos encontrar algunas fiestas y relaciones amorosas que son protegidas por la oscuridad -observándose, por tanto, un estrecho lazo con la noche-, en las cuales Hathor -Señora del desierto occidental- tiene un importante papel ${ }^{42}$.

37 Fue publicado bajo el título Das Todtenbuch der Ägypter, en 1842. Como tal, el Libro de los Muertos es una innovación moderna que recoge una multitud de fórmulas halladas, que debían ser recitadas por los difuntos.

38 Textos de las Pirámides, 705c. Otros pasajes con esta misma concepción son: 735, 130d, $1123 \mathrm{a}, 151$.

39 Textos de las Pirámides, declaración 211. Otros ejemplos: 408.714; 516.1185.

40 Textos de las Pirámides, declaración 44.

41 POSENER-KRIÉGER, P. (1970).

42 HORNUNG, E. (1956). Esta obra que se cita trata precisamente sobre la noche y la oscuridad en el Egipto faraónico. 
En textos sumerios también se dice que fue en la noche cuando el paraíso y la tierra fueron creados $^{43}$.

Por su parte, en la mitología griega, noche y día -encarnados como dioses- están contrapuestos, pero, al mismo tiempo, emparentados. Es decir, comparten un mismo origen, aunque la genealogía no era clara, dándonos cada autor sustanciales cambios, algo que ya observó el propio Cicerón ${ }^{44}$. De Caos, que a su vez deriva de la Oscuridad ${ }^{45}$, había nacido la Noche, nos dice la Teogonía. Los órficos la consideran como el comienzo de todo ${ }^{46}$. Otros, que Tártaro y Noche habían existido primero ${ }^{47}$, o que lo habían sido Caos y Noche, engendrando esta última el huevo del que nació Eros, el cual se unió a Caos, naciendo la raza humana que salió a la luz ${ }^{48}$. Y, de la misma forma, Ovidio afirma que en origen todo era noche y oscuridad ${ }^{49}$.

Volviendo a la Teogonía, Noche junto con su hermano Érebo -las tinieblas- habían engendrado a sus contrarios: Hémera ${ }^{50}-$ el día- y Éter -el aire claro-. En este aspecto, se concibe la noche como creadora del día -sin ella no podría existir- y, al mismo tiempo, relacionada como el destino, la muerte y lo negativo:

Parió la Noche al maldito Moro (la muerte señalada), a la negra Ker (el destino) y a Tánato (la muerte); pario también a Hipnos (el sueño) y engendró la tribu de los Sueños (Óneiroi). Luego además la diosa, la oscura Noche, dio a luz sin acostarse con nadie a la Burla, al doloroso Lamento y a las Hespérides [...]

Parió igualmente a las Moiras y las Keres, vengadoras implacables: a Cloto, a Láquesis y a Átropo que conceden a los mortales, cuando nacen, la posesión del bien y del mal y persiguen los delitos de hombres y dioses. Nunca

43 Enki and Ninmah: c.1.1.2.

44 Cic. Nat. D. 44. BERNET (1936) e Ídem (1937).

45 Higino, en Fábulas, considera que el Caos es hijo de la Oscuridad, mientras que Hesiodo, en la Teogonía (124-126), no lo menciona, aunque ambos mencionan la Noche y el Día como hijas del Caos.

46 Dam. Pr. 124.

47 Phld. Piet. 137.5.

48 Ar. Av. 693.

49 Ov. Met. 1.10-70.

50 En Hyg. Fab. pref. 1, Caos y Tinieblas habían dado lugar a la Noche, Día, Érebo y Éter, haciéndolas, por tanto, hermanas. 
cejan las diosas en su terrible cólera antes de aplicar un amargo castigo a quien comete delitos.

También alumbró a Némesis (la venganza divina), azote para los hombres mortales, la funesta Noche. Después de ella tuvo al Engaño, la Ternura y la funesta Vejezy engendró a la astuta Eris.

Por su parte la maldita Eris (la discordia) parió a la dolorosa Fatiga, al Olvido, al Hambre y los Dolores que causan Ilanto, a los Combates, Guerras, Matanzas, Masacres, Odios, Mentiras, Discursos, Ambigüedades, al Desorden y la Destrucción, compañeros inseparables, y al Juramento, el que más dolores proporciona a los hombres de la tierra siempre que alguno perjura voluntariamente $e^{51}$.

En pocas palabras, para los griegos la noche había engendrado todo tipo de males $^{52}$, incluida la muerte, lo que tampoco difiere en demasía con el pensamiento egipcio o de las culturas mesopotámicas. En palabras de Parménides: la noche es ciega, densa y pesada de cuerpo ${ }^{53}$. Y aunque para los romanos no exista un panteón articulado y una mitología como la griega, se pueden aplicar también estas características a la concepción romana de la noche como dejan ver Cicerón ${ }^{54}$-que, al fin y al cabo, recoge el mito griegoy Séneca. Este último, efectivamente, afirma:

Es durante el día cuando la sociedad lleva a cabo las tareas productivas, mientras que la noche es desde un punto de vista económico lo contrario ${ }^{55}$.

De hecho, la palabra latina nox se puede traducir también como «oscuridad, tinieblas, desorden, confusión; situación sombría turbada ${ }^{56}$.

51 Hes. Theog. 212-234.

52 Ciertos autores han afirmado que dicha maldad proviene por ser femenina, aunque como se podrá leer en los párrafos siguientes también tiene un carácter positivo, como ya hemos visto en el mundo egipcio. Sobre este tema se extiende en mayor aportación de datos PEREZ MIRANDA, I. y CARBÓ GARCÍA, J.R. (2009-2010), pp. 131-140.

53 Parm. 8.50-61.

54 Cic. Nat. D.: «¿Acaso puede negarse tal condición a su padre, Saturno, a quien se rinde culto como al que más entre el vulgo que habita occidente? Si éste es un dios, ha de reconocerse que también lo es su padre, cielo. Si esto es así, también los padres de Cielo han de ser tenidos por dioses, Éter y Día, así como sus hermanos y hermanas, a quienes los geneálogos antiguos denominan así: Amor, Engaño, Miedo, Fatiga, Envidia, Desino, Vejez, Muerte, Tinieblas, Miseria, Queja, Gracia, Fraude, obstinación, Parcas, Hespérides y Sueños. Cuentan que todos ellos nacieron de Érebo y Noche».

55 Sen. ep. 122.

56 SEGURA MUNGRÍA, S. (1985), p. 472; ERNOUT A. y MEILLET, A. (1985), p. 448. 
Virgilio la usa como sueño y tempestad, y para referirse a la Noche como divinidad. Cicerón lo hace como perturbación y calamidad; Ovidio como ceguera, pérdida de la vista ${ }^{57}$.

Día y Noche son incompatibles y sólo tienen un momento de encuentro, el cual es ante las puertas del Tártato -donde la Noche mora ${ }^{58}$-, en el lugar donde el hijo de Jápeto sostiene el cielo de pie, al cruzar el umbral de bronce. Ambas comparten, por tanto, morada ${ }^{59}$.

La noche era un momento de confusión. Trágicos hechos míticos ocurrieron en ella: Ágave despedazó durante la noche el cuerpo de Penteo ${ }^{60}$, en ella se produce la venganza de Épito ${ }^{61}$, Aedón mató por error a su hijo Ítilo confundido por la oscuridad ${ }^{62}$, la tragedia de Píramo y Tisbe tiene lugar en este periodo del día ${ }^{63}$, Troya fue tomada en la noche ${ }^{64}$ y también en ella se produjo la violación de Lucrecia ${ }^{65}$. Por exponer hechos históricos, fue en la noche cuando Epialtes traicionó a los espartanos en el paso de las Termópilas ${ }^{66}$, y cuando los Hermes de Atenas fueron mutilados ${ }^{67}$. Y otros tantos hechos podrían ser citados relacionados con la violación, el incesto, el mal uso del poder del pater familias, etc. ${ }^{68}$.

También en la noche actuaban monstruos, fantasmas, espectros ${ }^{69}$, como eran los Estriges ${ }^{70}$, los Manes $^{71}$, Larvas ${ }^{72}$, Lemures ${ }^{73}$, licántropos ${ }^{74}$, entre otros. Era el momento propicio para que brujas y hechiceras ${ }^{75}$ realizaran

57 DE MIGUEL, R. (1897): p. 614.

58 Hes. Theog. 745.

59 Hes. Theog. 747-761.

60 Eur. Bacch. 1119-1139.

61 Hyg. Fab. 137.2-6.

62 Escolio anónimo a la Odisea 19.518; Eust. Od. 1874.59.

63 Ov. Met. 4.55-166.

64 Verg. Aen. 2.250-267.

65 Livy, Epit. 1.57-58.

66 Hdt. 7.201-219.

67 Thuc. 6.27-28.

68 El tema es recogido, relacionando además a personajes femeninos con la noche, por LÓPEZ MEDINA, M. J. (2009-2010), pp. 110-124.

69 Tat. Ann. 2.24.4; Lucr. 129-135; Hor. Epist. 2.2.8-9; Plin. Ep. 7.27

70 Petron. Sat. 134.

71 Ov. Fast. 2.533-547.

72 Ov. Fast. 2.547-557; Verg. Aen. 10.633-642

73 Ov. Fast. 5.419-447.

74 Petron. Sat. 62.

75 Petron. Sat. 63; Apul. Met. 2.21-26; 2.30. 
hechizos y sortilegios ${ }^{76}$. Y era en la noche cuando tenían lugar ciertas ceremonias, muchas de ellas miradas con recelo, como los misterios de Osiris $^{77}$, las ceremonias dionisiacas ${ }^{78}$, los festivales trietéricos celebrados por las mujeres en Tracia ${ }^{79}$, así como las fiestas anuales en honor a Céres ${ }^{80}$ que también tenían un protagonismo femenino.

Sucedían también en la oscuridad hechos más mundanos como los incendios ${ }^{81}$-que añadían ese temor a la noche, pues recuérdese que el famoso incendio de Roma ocurrió en ella ${ }^{82}$. Era en la nocturnidad cuando borrachos $^{83} \mathrm{e}$ indeseables que buscaban trifulcas ${ }^{84}$ se apoderan de las calles, cuando los negocios más ocultos se realizan ${ }^{85}$, cuando se practicaban los juegos de $\operatorname{azar}^{86}$, y cuando pasiones ${ }^{87}$ e inmoralidades se abrían camino ${ }^{88}$.

Por otra parte, este negativismo de la noche era contagiado a otra serie de animales nocturnos, como las aves ${ }^{89}$-el búho, lechuza, cárabo común, etc. - , los cuales eran considerados de mal agüero ${ }^{90}$.

Pese a todo, al igual que ya hemos visto en el mundo egipcio, existe también una parte positiva en la noche -quizás menos clara que en Egipto-. Homero parece poner a la Noche por encima del resto de los dioses, pues al referirse a ésta comenta: «que rinde a dioses y a hombres» ${ }^{91}$. Algunos filósofos pensaron que la Noche, junto con el cielo y el caos, gobiernan,

76 Hor. Sat. 1.8.1-50.

77 Hdt. 2. 170-171.

78 Eur. Bacch. 485-487.

79 Ov. Met. 6. 588-593.

80 Ov. Met. 10. 431-436.

81 Juv. 3.5-9 y 198-201. El cuerpo de bomberos, instaurado por Augusto, realizaba sus rondas en la noche (Suet. Aug. 30.1).

82 Tat. Ann. 15.38.

83 Juv. 3.278-282; Mart. 12.12.

84 Suet. Otho. 2.1; Juv. 3. 290-299.

85 Juv. 8.158-162.

86 Prop. 2.33b.1-4.

87 Prop. 2.18b.3-14; Ov. Met. 11.201-317; 4.214-234; 9.454-499; 10.447-502; Apollod. Bibl. 2.4.8; Heraclit.Par. 38; Hyg. Fab. 23.3-4; 171.

88 Ov. Am. 1.4.53-59; 1.6.53-61; Cic. Cael. 20; Suet. Vit. Ner. 26; Juv. 3.275-278. Otros tantos ejemplos, relacionados con el engaño en la oscuridad, se encuentran en RUIZ DE ELVIRA, A. (1972), pp. 228-230.

89 Sobre el estudios de estas aves mencionadas y otras: ALVAR NUÑO, A. (2009-2010). 90 Ibíd. p. 188

91 Hom. Il. 14.258-261. En otro pasaje (16.258-261) se afirma: «La noche es terrible, sabia y poderosa, e incluso Zeus la respetal. 
mandan y originan el mundo ${ }^{92}$. Otros tantos creían que la noche era uno de los dos componentes de todas las $\cos ^{93}{ }^{93}$. Y algunos pitagóricos pensaban que luz y tinieblas eran uno de los diez principios de los seres ${ }^{94}$. La Noche es poseedora de sabiduría, según Escopeliano ${ }^{95}$; envidiándosela, pues, durante ésta es cuando Venus reluce ${ }^{96}$, cuando la Luna -identificada con Febe y Diana $^{97}$ - y las constelaciones que se corresponden con diversos dioses ${ }^{98}$ brillan. Además, es el momento en que los dioses pueden aprovechar para comunicarse con los hombres por distintos medios ${ }^{99}-\operatorname{como~los~sueños~}^{100}$ -

En los pasajes bíblicos ${ }^{101}$, la noche tiene también toda una serie de connotaciones negativas. Es símbolo de desgracia, de muerte, de pecado, de enfermedad, de sufrimiento, de demonios y de ignorancia ${ }^{102}$. Más adelante se entenderá como el momento para el alejamiento de Cristo ${ }^{103}$.

Sin embargo, la noche también tiene, de nuevo, una parte positiva ${ }^{104}$. Es un momento de oración y de encuentro con Dios. De hecho, fue en la noche cuando Dios liberó a su pueblo de Egipto ${ }^{105}$, el momento en que se le anunció a Abraham el nacimiento de su hijo, y cuando éste se dispuso a realizar el sacrificio.

Pero, en el mundo clásico, otros autores otorgan el origen de muchos males a Día. Higino nos dice que de Éter y de Día nacieron Tierra, Cielo

92 Arist., Metaph. 14.4.1091b.

93 Phld. Piet. 47a; Dam. Pr. 124.

94 Arist. Metaph. 1.5.986a.

95 Philostr. V.S. 1.21.518.

96 Men. Fr.739

97 Ov. Met. 2.411-416; 2. 454; 6. 216; 12.35-36; 15.196-198. Acerca de esta relación: LÓPEZ MEDINA, M.J. (2009-2010), pp. 106-107 y 109-110.

98 En la obra de Eratóstenes, Catasterismos, se recopilan las diferentes leyendas de éstas.

99 Livy, epit. 5.47.2-4

100 Ov. Met. 11.592-730; 8.634-654; 9.686-706; Hdt. 1.209-210; 5.55-56; 6.107-108; Suet. Iul. 81.3-4; Plut. Vit. Caes. 63.8-10; Plut. Vit. Brut. 48.1-4; Paus. 2.27.1-2; Ar. Plut. 640-745. No obstante el sueño también puede estar vinculado a la muerte como se observa en RODRIGUEZ FERNÁNDEZ, G. (2009-2010), pp. 154-164.

101 MEINERTZ, M. (1953).

102 Job. 35.10; 24.14; 7.9; Jn. 9.4; Lc. 12.39; Sal. 91,6; Mt. 13.25; Is. 15,1; Jer. 6.5

103 Podríamos destacar dos pasajes bíblicos bien conocidos que ocurrieron en la noche: el prendimiento de Jesús en el Huerto de los Olivos (Lc. 22.47-53; Mt. 27.47-56; Mc. 14.4352; Jn. 18.3-11) y la triple negación de Pedro (Mat. 26.69-75; Mc. 14. 66-72; Lc. 22.55-62; Jn. 18.25-27)

104 Gen. 15.5.17; 26.24; 28.11-13; Act. 12.6; 16.9; Ex. 11.4.

105 Ex. 12.37-42. 
y Mar, y que a su vez Éter y Tierra dieron lugar a: «Dolor, Engaño, Ira, Aflicción, Mentira, Juramento, Venganza, Intemperancia, Disputa, Olvido, Indolencia, Temor, Soberbia, Incesto, Combate, Océano, Temis, Tártaro, Ponto ${ }^{106}$. En todo caso, parece tener mayor relevancia la idea que recoge la Teogonía.

Ahora bien, los ejemplos hasta ahora expuestos son del mundo oriental y del mundo clásico, en donde por influencias - aunque no en todos los casosde las diversas culturas, la mayoría acabaron por tener estas semejanzas ideológicas, como es evidente. Si ahora observamos la concepción de noche y el día entre los celtas, veremos un cambio de creencias en este aspecto. Pero lo que está claro es que existe una división entre ambos momentos, independientemente de cómo se conciban.

El mundo celta y germano parece dar a la noche, ante todo, un carácter mucho más positivo. No obstante, básicamente las referencias a las creencias celtas provienen de autores romanos, por lo que nos falta una amplia información ${ }^{107}$. De cualquier modo, éstos hacen alusión a ceremonias que tenían lugar en la noche:

Algunos autores afirman que los galaicos son ateos, pero que los celtíberos $y$ los vecinos limitrofes al norte bailan y disfrutan la noche entera con toda la familia, en honor a un dios anónimo, de noche, durante los plenilunios, delante de las puertas de sus casas $^{108}$.

No se trata aquí de estudiar la referencia a ese dios innominado, del que durante un tiempo se vinculó a la Luna, y que otros autores han venido, en parte, a desmentir ${ }^{109}$. Si bien, se aprecia la celebración de una festividad con cierto carácter lúdico a lo largo de la noche. Ésta, por sí sola, no viene a demostrar nada -ya hemos visto en el mundo clásico festividades que tenían lugar en la noche-. Pero si hacemos referencia a una cita de César, éste nos comenta:

106 Hyg. Fab. pref. 2-3.

107 Se requeriría un estudio mucho más amplio acerca de la hipótesis que aquí se propone. Como comento, nos falta demasiada información directa como para considerar que los celtas dieran a la noche una connotación únicamente positiva, por mucho que lleváramos al extremo la famosa cita de Arriano (Anab.1.4.6), la cual indica que los celtas solo temían que el cielo se les cayese alguna vez encima.

108 Str. 3.4.16.

109 SOPEÑA GENZOR, G. (1995). p. 29; SOPEÑA GENZOR, G. y VICENTE RAMÓN, P. (1994), pp. 29-32 
Todos los galos se proclaman descendientes de Dis Pater y dicen que esa tradición les ha sido transmitida por los druidas. Por ello miden todos los periodos de tiempo no por el número de días, sino de noches; y así, tanto sus aniversarios como los inicios de meses y años los cuentan de forma que la noche precede al día ${ }^{110}$.

Si César realiza la interpretatio de ese dios galo, del que no da el nombre probablemente el Dagda irlandés y el Sucellos galo ${ }^{111}$-, al Dis Pater romano dios del mundo subterráneo-, ello se debe a que parte de sus características, algunas negativas para los romanos, pero no necesariamente para los galos, se asemejaban al mencionado Dis Pater. En eso pudo contribuir que su celebración se produjera en la noche, y que se plasma en la forma de contar los días. En unas mentalidades como hasta las ahora vistas, contar mediante las veces en que el Sol salía parece lo lógico, tal y como reza la Iliada: «Esta es el alba del décimo segundo día desde que llegué a Ilión» ${ }^{112}$. Pero para los celtas, era la noche la principal unidad para contar el tránsito de los días -ésta precede siempre al día ${ }^{113}$-, de tal modo que también meses y años comenzaban en la noche. La caída de la noche no es un fin, sino un principio, pues, si el dios innominado es realmente Dagda, éste es el gran guerrero portador del caldero, que es un símbolo regenerador pancéltico ${ }^{114}$.

También entre los germanos, según nos trasmite Tácito, se contaba por noches: «No cuentan como nosotros por días, sino por noches. Así establecen las fechas, así acuerdan sus citas: la noche parece preceder al día» ${ }^{115}$.

Aún hoy este antiguo cómputo queda de forma residual en inglés. La palabra quincena está formada por la palabra «noche», fortnight ${ }^{116}$. Y una arcaizante palabra inglesa: sennight ${ }^{117}$-semana-, prácticamente desconocida

110 Caes. B. Gall. 6.18.

111 MARCO SIMÓN, F. (2006), p. 61.

112 Hom. Il. 21.80-81.

113 No solo la noche precede al día, sino que la oscuridad parece que siempre precede a la luz. El año celta se divide en dos partes: una mitad sombría -momento en que se inicia el año celta, justamente con la llegada del frio- y otra luminosa -que correspondía con la llegada de un tiempo más cálido-. POWEL, T.G.E. (2005), p. 146

114 MARCO SIMÓN, F. (2006), p. 61

115 Tac. Germ. 11.

116 The Oxford English Dictionary (1989). Proviene de la unión de las palabras fourteen y night. 117 Ibíd. Proviene de la unión de las palabras seven y night. 
por quienes hablan aquel idioma, usa también la noche para contabilizar el paso del tiempo.

En cualquier caso, toda esta concepción religiosa de la noche y el día se remonta a los orígenes de la humanidad. La noche, más allá del imaginario creado, es peligrosa por sí misma. Sin luz, multitud de peligros - especialmente animales salvajes- acechaban a los hombres si éstos no buscaban un lugar seguro.

\section{DiVISIÓN EN HORAS}

El día y la noche, por otra parte, requerían también de unidades más pequeñas, conforme crecieron las necesidades de ordenación -ya sean éstas administrativas o religiosas-. Estas divisiones, popularmente conocidas como «horas» -y que deben ser entendidas de una forma distinta a nuestro moderno concepto del término- son del todo artificiales, es decir, no dependen de ningún ritmo astronómico ${ }^{118}$. Aunque, por otra parte, se buscó en la propia naturaleza -estrellas y Sol- la forma de medirlas.

Pero ¿en qué momento se crearon las «horas»? Se ha considerado que el día era ya dividido en época sumeria. En sumerio se encuentra la palabra danna o dana ${ }^{119}$-en asirio, el termino bèru tiene el mismo significado- que es la doceava parte del día y que equivale al tiempo estimado en que se tarda en cubrir una distancia de 1800 nindan $^{120}(10,8 \mathrm{~km})$, es decir, unas dos horas ${ }^{121}$. Sin embargo, tampoco sería una división tal, sino más bien la estimación del tiempo empleado en recorrer esa distancia. No parece que exista una intencionalidad en dividir el día en doce partes, especialmente porque parecen tener un origen egipcio.

Serían los egipcios los que por primera vez dividieran el día en veinticuatro partes o, más correctamente, la parte diurna en doce horas «estacionales» y la parte nocturna en otras doce. Lo primero que debemos observar es que estas unidades de tiempo -unut en egipcio antiguo- tienen una duración variable a lo largo del año, debido a que la división del día es independiente

118 HALLO, W.W. (1996), p. 121.

119 Según HALLORAN, J. (2006).

120 El nindan o ninda equivale a unos 6 metros.

121 ROCHBERG-HALTON, F. (1989), p. 147. 
a la noche, ya que tienen distinta naturaleza. Por tanto, en cuanto que en invierno los días son más $\operatorname{cortos}^{122}$, la duración de las horas del día se contraen -pero siguen existiendo doce partes-, mientras que las doce horas de la noche se extienden ${ }^{123}$ y viceversa - de ahí que se suela usar el término de horas «estacionales»-.

Una inscripción datada en el 1300 a.C., del cenotafio de Seti $\mathrm{I}^{124}$, en donde aparece un reloj de sol con su explicación, nos deja ver que el día era divido en diez partes iguales, sumándose una hora durante el tiempo de la salida del Sol y otra durante su puesta. En total, doce horas. Quizás esas diez primeras horas sean las de plenitud, encarnadas por Horajty, mientras que la primera hora estaría bajo la presidencia de Jepri y, las del anochecer, bajo Atum.

En todo caso, el uso de horas es mucho más antiguo a la datación del mencionado cenotafio, tal y como demuestra un fragmento de reloj solar egipcio, datado en el 1500 a.C., que se encuentra en el museo de Berlín. De hecho, Neugebauer considera que, si en origen el día era dividido en diez horas, esto estaba ya en desuso en el momento en que se hizo el cenotafio de Seti. En el 1300, por tanto, el día se dividía directamente en doce horas ${ }^{125}$.

Por otra parte, la noche, que recibía otra división de doce «horas», es representada por la pareja Kekut y Kek. La primera hora del anochecer está personificada por el primero, «el que trae la noche»; mientras que el segundo, «el que trae el cielo brillante», equivale a la última hora. En origen, Kek y su pareja femenina, Kekut, representaban la oscuridad primigenia según la Ogdoada hermopolitana ${ }^{126}$.

Algunos incluso afirman que, en principio, hacia el 2400 a.C. ${ }^{127}$, tan solo la noche sería dividida en doce partes iguales, tomando como referencia doce

122 La inscripción Inana and An: c.1.3.5 ya menciona: «la duración normal de la luz del día se acorta, y la luz del día se convierte en nochell.

123 Tomando como referencia el solsticio de verano actual, en Egipto sale ese día el sol a las 2:54 U.T.C y se pone a las 16:57 U.T.C. Mientras que el solsticio de invierno el sol sale a las 4: 46 U.T.C y se pone a las 10:57 U.T.C. Por tanto, el día más largo del año dura 14,3 horas, mientras que el día más corto es de 6,1 horas. Las doce horas egipcias durarían más de una hora en el verano, mientras que en el invierno no tendrían más de media hora.

124 Publicado por FRANKFORT , H., DE BUCK, A. y GUNN, B. (1933).

125 NEUGEBAUER, O. (1962) pp. 85-86.

126 FRANCO, I. (1994), pp. 76 y 95.

127 HANNAH, R. (2005), p. 87. 
estrellas -cambiantes cada diez días, por ello cada sistema de estrellas recibía el nombre de decanos- que aparecían a lo largo de la noche. A partir del Merkhet, un instrumento que permitía observar el paso de las estrellas por el meridiano, se conocía el tránsito de las horas ${ }^{128}$. Ello dio lugar a los llamados calendarios diagonales o relojes de estrellas diagonales ${ }^{129}$. Las primeras muestras de estos últimos se encuentran en las tapas de los sarcófagos de madera, que datan de la IX dinastía -lo que implicaría que la división horaria se había gestado en el último siglo del tercer milenio-, con el propósito de que el fallecido supiera la hora de noche o la fecha del calendario. Las horas estarían ya inventadas, por tanto, hacia el 2150 a.C. ${ }^{130}$.

Sea como fuere, dicha división podía entenderse como una forma de recrear, en el día y en la noche, los doce meses lunares del año ${ }^{131}$, sin que exista una relación con los sumerios y el sistema sexagesimal ${ }^{132}$. En definitiva, se trataría de una forma de recrear la regeneración anual del cosmos cada uno de los días como se ha indicado páginas atrás.

En los templos egipcios existía un sacerdote horario -según indican los textos de Karnak, Abidos y de los templos greco-romanos-; que observaba desde la terraza del templo el transcurrir de las horas, avisando de la llegada de un nuevo día y despertando al barrio de los servidores, quienes debían comenzar su trabajo. Los sacerdotes se purificaban en el lago del templo ${ }^{133} \mathrm{y}$, tras una entrada ceremonial en el edificio, se realizaba la ofrenda diaria. Cada día se celebraba la creación del mundo.

Además, en cada una de las horas, según muestra el Libro de la Noche y el Libro del Día, los sacerdotes recitaban determinadas y apropiadas palabras para el comienzo de cada hora -los tránsitos, en cualquier aspecto, siempre son peligrosos-. Se realizaba en nombre del faraón, en cuanto que su función

128 EBELING, E. y MEISSNER, B. (dir.) (2003-2005), p. 1811; NEUGEBAUER, O.

(1962) pp. 58, 81, 82, 84, 87, 88, 94.

129 ROCHBERG-HALTON (1992), p. 813.

130 PARKER, R.A. (1974), p. 53.

131 QUIRK, S. (2001), p. 42.

132 En este aspecto, parece que el sistema sexagesimal partiría de las doce lunaciones, que multiplicadas por cinco dan sesenta, a diferencia de las hipótesis que daba E. Hoppe (DINTZI, E. (1909) p. 118) que buscaba una base mucho más intelectual a partir del triángulo equilátero.

133 LÓPEZ, J., SANMARTÍN, J. en DEL OLMO LETE, G. (1993) p. 133. 
era la de mantener al Sol recorriendo el cielo y superar las dificultades del mundo subterráneo ${ }^{134}$.

Aún encontramos unidades mucho más pequeñas de tiempo en el Egipto faraónico, aunque su traducción tradicional podría llevarnos a confusión, sirviéndonos éstas más como una intuición de su significado que como su concepto original. En la tumba del arquitecto real Senenmut, en Deir elBahari, existe en su techo una relación de términos temporales que van desde el parpadeo - ant- a la eternidad -tchet-. Entre los términos inferiores a la hora - unut- se encuentra lo que ha sido traducido como minuto - at- y segundo - hat ${ }^{135}$.

Hacia el 1200 , se utilizaba ya un sistema parecido en Ugarit ${ }^{136}$. Ello implica que desde Egipto este modelo fue exportado a Mesopotamia y se difundió también por el Mediterráneo.

En Babilonia, las horas fueron llamadas simānu, término que significa también «tiempo»y «estación» ${ }^{137}$. Éstas estarán protegidas por cada uno de los planetas - entendiéndose éstos como los concebían en la Antigüedad, junto con el Sol y la Luna-, que se alternan en el siguiente orden: Saturno, Júpiter, Marte, Sol, Venus, Mercurio y Luna. El ciclo se vuelve a repetir en ese orden -por ello ningún día comienza presidido por el mismo planeta-.

Entre los hebreos, la palabra $\breve{s}^{-1} \bar{a} b^{138}$, que designa también a la hora, significa al mismo tiempo «momento » o «instante» ${ }^{139}$. Su uso parece bastante tardío $^{140}$, apareciendo especialmente en el Nuevo Testamento. También dividían el día en doce horas desde la salida del Sol, tal y como lo recuerda Jesús en la resurrección de Lázaro: «¿No son doce las horas del día? Si uno anda de día, no tropieza, porque ve la luz de este mundo; pero si uno anda de noche,

134 El ritual se conserva en estado fragmentario en el patio del templo funerario de Hatshepsut en Deir el-Bahari.

135 LLAGOSTERA, E. (2006-2007), p. 66.

136 DE JONG y VAN SOLDT (1989), p. 75.

137 El término lo da HALLO, W.W. (1996), p. 122. Sin embargo ni el The Assyrian Dictionary ni el Akkadisches Handwörterbuch dan una traducción concreta, aunque ambos determinan que es un término vinculado al tiempo.

138 Sólo se encuentran testimonios de su uso tardíamente y en arameo: Dan 4.16; 3.6.16; 4.3; 5.5 .

139 Mt. 8.13; 9.22; 10.19.

140 HAAG, H. (1987) p. 737. 
tropieza, porque no está la luz en él» ${ }^{141}$. En la Biblia, las horas son utilizadas para designar un momento concreto del día ${ }^{142}$, pero también como una medida temporal ${ }^{143}$. La noche, por el contrario, era dividida en vigilias ${ }^{144}$. En el Antiguo Testamento se habla de tres vigilias, las mismas divisiones que usaban los babilonios. De igual modo, éstas eran de distinta duración dependiendo de la época del año, aunque en el Nuevo Testamento se menciona la división romana, por la cual la noche era dividida en cuatro partes ${ }^{145}$. En Mesopotamia, encontramos una arcaica división: el día era dividido en cuatro periodos de seis horas ${ }^{146}$, es decir veinticuatro horas.

De hecho, lo más habitual era realizar divisiones mucho más sencillas -especialmente del periodo diurno- como demuestran estos últimos ejemplos que, por lógica, debemos remontar a la Prehistoria. Así, los hebreos dividieron las horas de sol en tres partes - mañana, mediodía y tarde-. En hebreo, éstas son böqer-mañana-, sŏhŏrayim -mediodía- y 'ereb-tarde- ${ }^{147}$. Los romanos lo dividieron en ante meridiem y de meridium, siendo la séptima hora la que señalaba el mediodía ${ }^{148}$. Y la noche, dividida en cuatro vigilias enumeradas por números -siendo también la séptima hora, esta vez de la noche, la que dividía ésta en dos mitades-, se relacionaba con las guardias

141 Jn. 11.9.

142 Mt. 20.3; Mc. 15.5; Act. 2.15; Act. 19.9; Mt. 20.5; Mt. 27.45; Mc. 15.33; Lc. 23.44; Jn. 4.6; Jn. 19.14; Act. 10.9; Jn. 4.52; Mt. 20.5; Mt. 27.45; Act. 3.1; Act. 10.3; Jn. 1.39; Act. 19.9; Mt. 20.6.9.

143 Mt. 20.12; Mt. 26.40; Mc. 14.37; Lc. 22.59; Ap. 17.12; Ap. 18.10;16.19.

144 Act. 23.23; Ex 14.24.1; Sam. 11.11; Jue. 7.19.

145 Mc. 13.35; Lc. 12.38; Mt. 14.25; Mc. 6.48.

146 ENGLUND, R. K. (1988), p. 168.

147 Sal. 55.18.

148 Oficialmente para los romanos el día comenzaba en la séptima hora de la noche. Macrobio (1.13.12-15) nos da las divisiones: «El día civil se divide de la siguiente manera: el primer momento del día se llama "la noche declina hacia el día" (media noctis inclinatio); el siguiente, "el canto del gallo" (gallicinium); luego, "el silencio" (conticuum), cuando los gallos se callan y también los hombres duermen todavía; después, "las claras del día" (diluculum), esto es, cuando se empieza a percibir el día; luego, "la mañana" (mane), cuando el día está luminoso. [...] Luego, el momento que se extiende de la mañana al mediodía (a mene ad meridiem), esto es, hasta la mitad del día; luego, se llama ya "tiempo declinante" (tempus occiduum), y luego "último tiempo" (extrema tempestas) [...] Luego está "la tarde", vespera, un préstamo del griego. En griego, en efecto, hespera deriva de Héspero, la estrella de la tarde; de aquí viene que Italia sea llamada también Hesperia, porque está situada bajo la región del ocaso. El momento siguiente recibe el nombre de "la primera antorcha" (prima fax), el siguiente "la hora de acostarse" (concubia), y el posterior "las horas intempestivas", porque es un tiempo inapropiado para cualquier actividad». 
en los campamentos. Si hacemos caso a Plinio ${ }^{149}$, éste nos comunica que el primer reloj de sol fue construido en el 293 a.C., lo que deja ver que la organización del tiempo en horas no tenía, en sí, gran importancia para la vida cotidiana, aunque como nos dice Aristófanes, la propia sombra de un hombre servía para saber el momento del día ${ }^{150}$.

Desde Egipto y Mesopotamia, la división del día en horas «estacionales» pasó al mundo griego. Así nos los dice Heródoto: «Pues el polo, el gnōmōn y la división del día en doce partes los griegos lo aprendieron de los babilonios ${ }^{151}$. En Grecia encontramos tal división en época clásica, aunque de forma tardía, en donde cada una de las doce divisiones del día -que no de la noche- estaban presididas por doce Horas, término que tomó el latín de forma directa ${ }^{152}$. Aunque en su origen éstas habían sido las divinidades de las estaciones: Eunomía, Dike y Eirene ${ }^{153}$, que encarnaban a la Disciplina, la Justicia y la Paz respectivamente, siendo hijas de Zeus y Temis. De esta manera, representaban a la naturaleza y al orden social; al cabo, eso es lo que representa el tiempo.

La creación de estas divinidades es relativamente tardía, lo que hace ver que las horas fueron claramente heredaras por los griegos, pues no aparecen mencionadas en la segunda mitad del siglo IV a.C. ${ }^{154}$, y posteriormente pasarán al mundo romano posiblemente por intermediación de los etruscos, de quienes tradicionalmente se ha dicho aprendieron los romanos la astronomía.

Estas Horas eran: Auge, la primera luz; Anatole, amanecer; Música o Musia, la hora matutina de la música y el estudio; Gymnastica o Gymnasia, la hora matutina de la gimnasia y el ejercicio; Nymphe o Nymphes, la hora

149 Plin. HN. 7.213.

150 Ar. Eccl. 652.

151 Hdt. 2.109.3.

152 ERNOUT, A. y MEILLET, A. (1985), p. 299. El término fue heredado por culturas más occidentales a la romana. En irlandés «uar», en inglés «hour»-esta última proveniente del brítano «awr»- y probablemente la palabra germana «Uhr». DEMANDT, A. (2002), p. 138.

153 Hes. Theog. 901; Pind. Fr. 30; Pi. O. 13.6; Apollod. Bibl. 1.3.1. Para Hesiodo, las Horas protegen las cosechas, y de hecho los atenienses las llamaban Talo, Auxo y Carpo (Paus. 9.35.2), que significa brotar, crecer y fructificar. En la Iliada nos la encontramos como las protectoras de las puertas divinas del Olimpo (5.749; 8.393). Aparecen en ocasiones realizando distintas tareas (Ov. Met. 2.118) Poseían un santuario (Paus. 2. 20.5).

154 BICKERMAN, E. J. (1968), p. 15. 
matutina de las abluciones; Mesembria, mediodía; Esponde, las libaciones vertidas tras el almuerzo; Elete o Telete, oración, la primera de las horas de trabajo de la tarde; Acte o Acme, comida y placer, la segunda de las horas de trabajo de la tarde; Hesperis, atardecer; Dysis, ocaso; Arktos, la última luz ${ }^{155}$. Se puede observar que hay una correspondencia con los momentos en que se realizaban ciertas actividades. Por otra parte, el mismo autor, Higino, que menciona dichas horas en sus fábulas, nombra también a otras: «Estos son los nombres de las Horas, hijas de Júpiter, hijo de Saturno, y de la Titánide Temis: Auxo, Eunomia, Ferusa, Carpo, Dice, Euporie, Irene, Ortosie y Talo» ${ }^{156}$.

Respecto a Auge y Arktos, primera y última luz del día respectivamente, recuerda al mundo egipcio con las dos divinidades que presidían estos dos momentos tal y como se acaba de comentar pocos párrafos más arriba.

Cambiando de perspectiva, el uso de horas equinocciales -las horas que hoy en día usamos-, es decir, periodos iguales de tiempo tanto en la noche como en el día, es muy tardío, del siglo XIV d.C. ${ }^{157}$. Pese a todo, éstas fueron ideadas por el Helenismo, atribuidas a Hiparco ${ }^{158}$, en el siglo II a.C., que tomaría, en todo caso, los modelos egipcios y mesopotámicos ${ }^{159}$. Sin embargo, Neugebauer creía que en la primera parte del primer milenio a.C. se comenzaron a utilizar las horas equinocciales ${ }^{160}$, como consecuencia del uso de los relojes de agua en tiempos del rey Nabonassar de Babilonia ${ }^{161}$, aunque las clepsidras son también un invento egipcio. Su uso se extendió más tarde a Mesopotamia y al mundo clásico ${ }^{162}$. En sumerio, estos mecanismos son conocidos como girs-dib-dib, giss-lidda, girs-nig-ninda ${ }_{2}$ o girs-KAB-az; y dibdibbu o maltaketu en acadio ${ }^{163}$.

En parte, la argumentación de este investigador es lógica, en cuanto

155 Hyg. Fab. 183.5 .

156 Hyg. Fab. 183.4.

157 DEMANDT, A. (2002), p. 138.

158 Str. 2.5.36.

159 ROCHBERG-HALTON (1989), p. 151. Ya mencionado por NEUGEBAUER, O. (1962), p. 81

160 NEUGEBAUER, O. (1947), p. 245. Llamadas así puesto que en los equinoccios el día y la noche tienen la misma duración, por ello aequinox, de donde proviene nuestra palabra, significa «noche igual».

161 HALLO, W.W. (1996), p. 124.

162 Caes. B Gall. 5.13.

163 HALLO, W.W. (1996), p. 124. 
que dichos mecanismos darían siempre unas unidades de tiempo similares, independientemente de la estación del año. Sin embargo, estos relojes fueron utilizados normalmente en la noche, y debían ser regulados al menos cada mes para que dieran la hora solar, de acuerdo a la duración más larga o corta de los días. Así lo dice Vitrubio en época clásica:

En estos relojes de agua, las horas quedan señaladas en una columna o pilastra; una figurita, que va ascendiendo desde la parte más baja, indica con una varita las horas de todo un día. La duración más corta o más larga de los días obliga a añadir o a quitar unas cuñas cada día y cada mes. [...]

Si no se está muy conforme con este método de alargar o acortar la duración de los días apretando o aflojando los conos - dado que con frecuencia provocan averías o son defectuosos - se optará por la siguiente solución: se señalarán las horas en una pequeña columna oblicuamente, conforme al analema, $e$ igualmente se marcarán las líneas que delimiten los meses. Esta columna debe ser giratoria, de modo que, al ir virando ininterrumpidamente, haga girar la estatuilla y la varita - la varita de la estatuilla señala las horas conforme va elevándose-y así indicará la mayor o menor duración de las horas, en cada uno de los meses ${ }^{164}$.

El sistema de periodos iguales deriva del propio sistema anteriormente visto, pues en los equinoccios, al ser igual la noche que el día, las doce divisiones de ambos duraban lo mismo. Sin embargo, éste no dejaría de ser un modelo teórico que no sería utilizado hasta el siglo XIV d.C., con la revolución del reloj ${ }^{165}$. Así, por ejemplo, las usa Plinio cuando dice: «por el diferente crecimiento de las horas de luz, en Méroe el día más largo abarca doce horas equinocciales más ocho partes de otra hora; en Alejandría, catorce horas; en Italia quince; diecisiete en Britania, $[\ldots]{ }^{166}$

\section{Medir las horas y SU IMPORTANCiA}

El sistema para medir las horas durante el día, por tanto, era mediante el reloj de sol, así como el gnomon-de donde surgiría el reloj de sol en el modo en que se nos ha transmitido a nosotros-, que ya es encontrado entre los sumerios - pese a su nombre griego-, e incluso se ha intentado identificar el

164 Vitr. De arch. 9.8.

165 BOORSTIN, D.J. (1983), pp. 39-42.

166 Plin. HN 2.75.186. 
término que estos usaban: $u_{4}$-sakar en sumerio, mientras que para los acadios es uskaru o askaru. Y mucha más información se tiene sobre los relojes de sol babilonios, conservándose incluso tablillas en donde se dice como se deben construir ${ }^{167}$.

Dice Arato, cuando trata sobre el cuarto círculo o Zodiaco:

En él se hallan el Cangrejo, a continuación el León y después la Virgen; también se encuentran las Pinazas y el propio Escorpión, el Sagitario y el Capricornio, y después del Capricornio, el Acuario; a continuación del cual se encuentra el resplandeciente asterismo de los dos Peces; después de ellos el Carnero, el Toro y los Gemelos. El Sol los atraviesa a todos, a las doce, en su progresión anual completa, y al marchar en torno a este círculo prosperan todas las fructiferas estaciones. Igual porción de círculo se sumerge en el cóncavo Océano, como gira por encima de la Tierra; todas las noches, sin falta, seis doceavas partes del círculo se ponen, y otras tantas se levantan. Cada noche dura siempre tanto tiempo como la mitad del círculo necesita, a partir de la caída de la noche, para elevarse por encima de la Tierra ${ }^{168}$.

En este sentido, los griegos usaron estos signos para determinar las horas durante la noche -ya hemos visto cómo los egipcios también utilizaron las estrellas para esto mismo-.

Cabría preguntarse hasta qué punto era importante la organización temporal del día. Evidentemente, el control de las horas es mucho más complejo y probablemente eran utilizadas de una forma mucho menos regular de lo que hoy las utilizamos, aunque para unas sociedades sumergidas en el zodiaco, el conocer la hora exacta de nacimiento de un individuo era totalmente necesaria. Pero lo que queda claro es el uso de éstas, como bien atestigua la proliferación de relojes de sol $^{169}$, especialmente en época clásica. Vitrubio da toda una serie de tipologías de relojes de sol junto con sus inventores -aunque estos últimos no sean realmente tales-:

Se dice que el inventor del Hemiciclo excavado en un bloque cuadrado o en un cubo, de acuerdo con la latitud, fue Beroso de Caldea; Aristarco de Samos fue el inventor - dice- del espejo cóncavo o hemisférico y también del disco colocado sobre una superficie plana. El astrónomo Eudoxo inventó la araña,

167 ROCHBERG-HALTON (1989), pp. 162-165.

168 Arat. 545-559.

169 Plinio (HN 2.76) considera que el reloj de sol, llamado esciotérico, lo descubrió Anaximandro. 
aunque otros opinan que fue Apolonio. Escopinas de Siracusa ideó el plintio o artesonado, que todavía ahora podemos ver en el circo Flaminio. Teodosio y Andrias son los inventores del reloj para cualquier latitud; a Patroclo se debe la invención del reloj en forma de hacha de combate; Dionisodoro ideó el reloj solar en forma cónica y Apolonio el reloj en forma de carcaj. Todos estos inventores citados y otros muchos idearon diversos modelos de relojes, que nos han transmitido, como son la araña cónica, el plintio cónico, y el antiboreo ${ }^{170}$.

No obstante, la teoría de la sombra que proyecta el sol era ya conocida desde la Prehistoria - a la Antigüedad sólo le debemos dar gracias por la sofisticación de los mecanismos-. Por ejemplo, los aborígenes australianos colocan una piedra en la horquilla de un árbol, conociendo el momento del día cuando la sombra cae sobre ella. $\mathrm{O}$ en ciertas tribus de los trópicos se usa la longitud de la sombra ${ }^{171}$.

En cuanto a la forma de computar el día, ésta difiere como vemos en Plinio: «los babilonios entre una salida de sol y otra, los atenienses entre sus dos ocasos, los umbros de mediodía a mediodía, el vulgo en general desde el amanecer hasta la noche, los sacerdotes romanos y quienes delimitaron el día civil, además de los egipcios e Hiparco, de medianoche a medianoche» ${ }^{172}$. Coincide en ciertos aspectos con Aulo Gelio ${ }^{173}$, en el caso de los atenienses ${ }^{174}$ y los babilonios: «mucha gente habla del mismo día a partir de un medio día hasta el medio día siguiente». Como dice el propio Plinio, debemos pensar que ésta es una división civil o, lo que es lo mismo, administrativa, mientras que el pueblo -a excepción de los celtas- considera que el día comienza por la mañana y acaba en la noche. De hecho, las horas romanas eran enumeradas en el comienzo del día, y volvían a ser enumeradas en el comienzo de la noche ${ }^{175}$.

170 Vitr. De Arch. 9.8.

171 WHITROW, G.J. (1990), p. 30.

172 Plin. HN 2.77.

173 Gell. NA3.2.4-6.

174 Información recogida también por Macrob. Sat.1.3.4: «El mismo Varrón, en el mismo libro, dejó escrito que los atenienses tenían otra consideración al respecto, y que para ellos, todo el tiempo que media desde el ocaso del sol hasta que el sol se pone de nuevo constituye un solo día; que también los babilonios tenían su particular consideración, pues daban el nombre de día, un mismo día, al espacio de tiempo que va desde el orto del sol hasta el momento en que empieza de nuevo a salir; y que los umbros, por su parte, consideran que es un único y mismo día el espacio de tiempo que va desde el mediodía al mediodía siguiente».

175 También Paulo, en el Digesto (2.12.8), menciona: «Según la costumbre romana, el día 
Pero fijar una frontera entre dos días - entendido ahora el día como las veinticuatro horas- era una necesidad, especialmente para fijar el día del nacimiento ${ }^{176}$. Así lo muestra Aulo Gelio, quien además cita a Varrón ${ }^{177}$ :

Suele preguntarse cuál debe ser considerado como día natalicio de quienes han nacido en la hora tercera o cuarta o en cualquier otra hora de la noche, si el día precedente a esa noche o el día siguiente. En su obra Antigüedades bumanas, en el libro dedicado a los días, Varrón escribe asi: 'Los hombres nacidos en las veinticuatro horas a partir de la media noche hasta la media noche siguiente se considera nacidos en el mismo día'. Con estas palabras parece haber dividido el cómputo de los días de manera que el día natalicio de quien haya nacido tras la puesta de sol y antes de la media noche será el día que precede a esa noche; en cambio, quien nazca en las seis horas siguientes se considera que ha nacido en el día que ha amanecido después de esa noche ${ }^{178}$.

Y volviendo a los umbros, nos cuenta Gelio por boca de Varrón:

Entre los umbros quien ha nacido en la hora sexta de las calendas parece que debe considerar día natalicio suyo tanto la segunda mitad del día de las calendas como también el día siguiente a las calendas hasta su hora sexta ${ }^{179}$.

Además de fijar el día de nacimiento, en el caso de las ceremonias nocturnas, éstas se asignaban al día y no a las noches. Y, de igual modo, cuando los augures debían tomar auspicios, estos comenzaban a partir de la media noche, es decir, de la hora séptima, puesto que se consideraba que ya era el día siguiente ${ }^{180}$. También el tiempo durante el que los Tribunos de la Plebe podían ausentarse de Roma, no más de un día entero, se computaba desde la hora séptima de la noche hasta la siguiente hora séptima de la noche ${ }^{181}$. Y numerosas disposiciones legales requerían el conocer cuándo comenzaba un día y cuándo otro ${ }^{182}$, o la prohibición de ciertas actividades -

comienza a medio noche y concluye a la media noche siguiente». Macrob. Sat. 1.3.6.

176 Aunque probablemente de dudosa veracidad, al contar los umbros los días de mediodía a mediodía, Macrobio (1.3.5) cree que «si un individuo nació el día de las calendas a la hora sexta, su día de nacimiento, al parecer, deberá repartirse entre la mitad del día de las calendas y el día siguiente al de las calendas hasta la hora sexta de dicho díal.

177 Varro, Sat. Men. 1.13. El fragmento es también recogido por Macrob. Sat. 1, 3, 2-3.

178 Gell. NA3.2.1-3.

179 Gell. NA3.2.6.

180 Macrob. Sat. 1.3.7.

181 Macrob. Sat. 1.3.8.

182 Gell. NA3.2.7-16. 
los oficiales romanos no hacían tratos ni acuerdos después del mediodía ${ }^{183}$. Pero esto era el día civil ${ }^{184}$, dies civilis, del que nos habla Varrón ${ }^{185}$, usado únicamente para diferenciar las partes del día que no estaban del todo claras.

Así, por ejemplo, parece difícil determinar el momento exacto en que cae la noche y se produce el alba. Volviendo a mencionar las cuestiones romanas de Plutarco, éste alega:

Puesto que la mayoría define por percepción como comienzo del día el primer atisbo de sol y como principio de la noche el ocultamiento del último rayo solar, no tendremos equinoccio sino que la noche que consideramos más equiparable al día se muestra más corta que éste a causa del tamaño del sol. Pero a su vez lo que los matemáticos para subsanar esta anomalía suponen, a saber, que cuando el centro del sol toca el horizonte estamos en la frontera entre el dia y la noche, es una negación de la evidencia; pues sucederá que cuando aún haya mucha luz sobre la tierra y el sol brille sobre nosotros, no se podrá convenir que es de dia porque aún es de noche. Pues bien, puesto que por las salidas y puestas del sol es difícil de determinar el principio del dia por las contradicciones mencionadas, queda reconocer como principio del día el cenit o el nadir. Y lo segundo es mejor; pues del mediodía a la puesta, el sol se aleja de nosotros, y de la medianoche, en cambio, a su salida viene hacia nosotros ${ }^{186}$.

\section{Conclusiones}

En una breve conclusión, se puede decir que la concepción de día y noche no era entendida en la Antigüedad como un conjunto, aunque sí comenzó a serlo para los estudiosos. Más allá de ello, se observa la diferencia de ambos momentos en la forma en que las distintas cosmogonías de la Antigüedad explican el origen de ambos, dando a la noche un papel, en cierta medida, creadora del mundo. Pero, pese a ello, la noche es entendida ante todo como un momento peligroso para los hombres, los dioses, e incluso para el mantenimiento del orden cósmico, bajo la amenaza permanente de ruptura.

183 Plut. Quaest. Rom. 84d.

184 El asunto también es tratado por Plutarco en las Cuestiones romanas 84. El autor se pregunta acerca de ello, creyendo que tal vez tenga un origen militar. De esta forma, era durante la noche cuando se iniciaban los preparativos, siendo el amanecer el principio de la actividad y la noche el principio de preparación. Referencias al asunto aparecen en Macrob. Sat. 1.3.10.

185 Varro, Ling. 3.12.14.

186 Plut. Quaest. Rom. 84e 
No obstante, se puede observar en el mundo celta un carácter más positivo de la noche, aunque tampoco hay fuentes que, de forma directa, vengan a afirmarlo.

Entendidas estas diferencias, se puede explicar por qué la Antigüedad dividió el día, no en veinticuatro horas, sino en doce partes nocturnas y doce diurnas, llamadas horas estacionales, cuya duración variaba a lo largo de las estaciones. Relojes de sol y de agua funcionaban de acuerdo a ello -aunque la propia sombra que proyectaban los objetos, así como las estrellas en la noche permitían conocer el tránsito de éstas-, y, siguiendo las evidencias, fueron los egipcios los primeros en realizar esta partición, que superó a las divisiones naturales del día y de la noche. Las horas se extendieron primero por el Próximo Oriente y, más tarde, al mundo clásico.

De cualquier modo, el conocer cuándo comenzaba y acababa el día no fue algo homogéneo ni en las mismas culturas, al menos para las funciones administrativas y también algunos aspectos religiosos como el nacimiento. No obstante, la tendencia general, al menos para el pueblo, fue considerar el inicio del día el momento en que el Sol aparecía en el Este, y que el día había acabado cuando éste se ponía. La negra noche penetraba entonces en la tierra.

\section{Bibliografía}

ALVAR EZQUERRA, J. (2009-2010): «La Construcción del imaginario: Las criaturas de la noche», Arys 8, pp. 17-37.

ALVAR NUÑO, A. (2009-2010): «Nocturnae Aves: su simbolismo religioso y función mágica en el mundo romano», Arys 8, pp. 187-202.

BERNET (1936): «Nox», Pauly, vol. XVII1, p. 1229.

BERNET (1937): «Nyx», Pauly, vol. XVII2, p. 1663.

BICKERMAN E.J. (1980): Chronology of the Ancient World, Thames and Hudson, Londres .

BOORSTIN, D.J. (1983): Los descubridores, Crítica, Barcelona. 
BUCHNER, E. (1982): Die Sonnenubr des Augustus, Mainz.

CARBÓ GARCÍA, J.R. y PÉREZ MIRANDA, I. (2009-2010): «Hijas de la noche (I): mito, género y nocturnidad en la Grecia Antigua», Arys 8, pp. 129-140.

CARBÓ GARCÍA, J.R. y PÉREZ MIRANDA, I. (2009-2010): «Hijas de la noche (II): el destino de las Parcas entre el pasado y el presente», Arys 8, pp. 141-154.

CHANTRAINE, P. (1999): Dictionnaire étymologique de la langue grecque: histoire des mots, Klincksieck, París

DEMANDT, A. (2002): «Zeit in der Antike. Vergangenes und Gebliebenes", en FALK, H., Sonderdruck aus Vom Herrscher zur Dynastie, Zum Wesenkontinuierlicher Zeitrechnung in Antike und Gegenwart. Hempen Verlag, Brenen, pp. 138-152.

DINTZI, E. (1909): «The Salzburg meeting of the Deutsche Mathematiker Vereinigung", Bulletin of the American Mathematical Society 16, No 3, pp. 114121.

EBELING, E. y MEISSNER, B. (dir.) (2003-2005): Reallexikon der Assyriologie und Vorderasiatischen Archäologie, Berlín.

ENGLUND, R. K. (1988): «Administrative Timekeeping in Ancient Mesopotamia», JESHO 31, pp. 121-185.

ERNOUT A., MEILLET, A. (1985): Dictionnaire étymologique de la Langue Latine, Histoire des mots, París.

FRANCO, I. (1994): Pequeño diccionario de mitología egipcia, José J. de Olañeta, D.L, Barcelona.

FRANKFORT, H. (1998): La religión del antiguo Egipto, Laertes, Barcelona.

FRANKFORT, H., DE BUCK, A. y GUNN, B. (1933): The Cenotaph of Seti $I$ at Abydos, 2 vols. Memoir of the Egypt Exploration Society, Egypt Exploration Society. Londres. 
LE GOFF, J. (1991): El orden de la memoria. El tiempo como imaginario, Paidós Básica, Barcelona, (edición original de 1977).

HALLO, W.W. (1996): Origins: the Ancient Near Eastern Background of Some Modern Western Institutions, E.J. Brill, New York.

HALLORAN, J. (2006): Sumerian Lexicon: a Dictionary Guide to the Ancient Sumerian Language, Logogram Pub, Los Ángeles.

HANNAH. R. (2005): Greek and Roman Calendars, Duckworth, Londres.

HAAG, H. (1987): Diccionario de la Biblia, Herder, Barcelona

HIDALGO DE LA VEGA, M.J. (2009-2010): «Larvas, Lemures, Manes en la demonología de Apuleyo y la creencias populares de los romanos», Arys 8, pp. $165-186$.

HORNUNG, E. (1956): Nacht und Finsternis im Weltbild der alten Ägypter, Tübingen.

HORNUNG, E. (1999): El Uno y los Múltiples. Concepción egipcia de la divinidad, Trotta, Madrid.

DE JONG, T. y van SOLDT, W.H. (1989): «Redating an Early Solar Eclipse Record (KTU 1.78): Implications for the Ugartic Calendar and for the Secular Accelerations of the Earth and Moon", JEOL 30, pp. 65-77.

LARA PEINADO, F. (1989): Libro de los Muertos, Tecnos, Madrid.

LLAGOSTERA, E. (2006-2007): «La medición del tiempo en la Antigüedad. El calendario egipcio y sus herederos, el Juliano y el Gregoriano»; Espacio, Tiempo y Forma. Serie II, Historia Antigua, t. 19-20, pp. 61-76.

LÓPEZ MEDINA, M.J. (2009-2010): «Diana y otras criaturas de la noche en la Metamorfosis de Ovidio", Arys 8, pp. 101-129.

MARCO SIMÓN, F. (2006): Los celtas, Historia 16, Madrid.

MARCO SIMÓN, F. (1988): Illud Tempus. Mito y cosmogonía en el mundo antiguo. Universidad de Zaragoza 
MEINERTZ, M. (1953): «Die 'Nacht' im Johannesevangelium», Theol. Quart. Schriff, 122, pp. 400 y ss.

DE MIGUEL, R. (1897): Nuevo diccionario latino-español etimológico, Madrid.

NEUGEBAUER, O. (1947) : «Studies in ancient astronomy. VIII. The water clock in Abaylonian astronomy», Isis 37, pp. 37-43.

NEUGEBAUER, O. (1962): The Exact Sciences in Antiquity, Providence, Brown U.P.

NEUGEBAUER, O. y PARKER, R.A. (1960): Egyptian Astronomical Texts I, Londres

DEL OLMO LETE, G. (dir.) (1999): Mitología y religión del Oriente Antiguo, AUSA, D.L., Sabadell

The Oxford English Dictionary (2a Ed.)(1989), Clarendon Press, Oxford

PARKER, R. (1950): The Calendars of Ancient Egypt, Chicago.

PARKER, R. A. (1974): «Ancient Egyptian Astronomy», en HODSON, F.R. (ED), The Place of Astronomy in the Ancient World, The British Academy and Oxford University Press, Londres, pp. 51-65.

PLÁCIDO SUAREZ, D. (2009-2010): «La Noche en la Cosmogonía de Hesíodo", Arys 8, pp. 35-42.

POSENER-KRIÉGER, P. (1970): «La nuit de Re», Revue d’Egypotologie 22, pp. 131-137.

POWELL, T.G.E. (2005): Los celtas, Oberon, Madrid (original de 1958)

QUIRK, S. (2001): The Cult of Ra: Sun-worship in Ancient Egypt, Thames and Hudson, Londres.

RAMNOUX, C. (1959): La Nuit et les enfants de la Nuit, Paris.

ROCHBERG-HALTON F. (1992): «Calendars: Ancient Near East», en FREEDMAN D.N. (ed), The Anchor Bible Dictionary, New york, Doubleday, pp. $810-814$. 
ROCHBERG-HALTON, F. (1989): «Babylonian Seasonal Hours», Centaurus 32, pp. 146-170.

RODRÍGUEZ FERNÁNDEZ, G. (2009-2010): «Sueño y muerte: dos hijos de la noche en el mito de Reso», Arys 8, pp. 155-165.

RUIZ DE ELVIRA, A. (1972): «Las grandes sagas heroicas y los cuentos populares", Citad. Fibol. Chis. Estudios Latinos, no 1 extraordinario: pp. 227235, 2001 (Publicado originalmente en JANO 39).

SEGURA MUNGRÍA, S. (1985): Diccionario etimológico latino-español, Anaya, Madrid.

SODEN, W. von (1966): Akkadisches Handwörterbuch, Harrassowitz, Wiesbaden.

SOPEÑA GENZOR, G. (1995): Ética y Ritual. Aproximación al estudio de la religiosidad de los pueblos celtíberos. Institución Fernando el Católico, Zaragoza.

SOPEÑA GENZOR, G. y VICENTE RAMÓN, P. (1994): «El anonimato de un dios de los celtíberos: aportaciones críticas en torno a Estrabón III,4,6», Studia Storica-Historia Antigua 12, pp. 21-34

VALDÉS GUÍA, M. (2009-2010): «Las Mujeres y la noche en los rituales griegos: las seguidoras de Dioniso en Atenas», Arys 8, pp. 43-60.

VV.AA. (Grupo Tempe) (2008): El reino de la noche en la Antigüedad, Alianza Editorial, Madrid.

WHITROW, G. J. (1990): El tiempo en la Historia, Crítica, Barcelona. 